DOI: http://dx.doi.org/10.20435/1117

\title{
O comportamento do consumidor de automóveis
}

Cars consumer's behavior

Renan da Cunha Soares Júnior ${ }^{1}$

Ana Cristina Alves Lima ${ }^{2}$

Heloisa Bruna Grubits Freire ${ }^{3}$

${ }^{1}$ Psicólogo, Especialista em Psicologia do Trânsito e Psicologia da Comunicação. Mestre em Psicologia, Aluno do Doutorado em Psicologia da Universidade Católica Dom Bosco. E-mail: renanjr@gmail.com

${ }^{2}$ Psicóloga e Mestre em Psicologia pela Pontifícia Universidade Católica de Campinas. Atualmente é Professora do Centro Universitário de Araraquara e Coordenadora da Pós-Graduação EAD-Psicologia do Centro Universitário de Araraquara. E-mail: coordeadpsico@gmail.com

${ }^{3}$ Psicóloga, Mestre em Psicologia e Doutora em Ciências Biomédicas. Professora do Programa de Pós-Graduação Mestrado e Doutorado em Psicologia da Universidade Católica Dom Bosco. E-mail: grubitshb@hotmail.com 


\section{RESUMO ABSTRACT}

0 presente trabalho versa sobre o comportamento dos consumidores de automóveis. Foi realizada uma pesquisa de artigos, dissertações e teses, utilizando ferramentas como o Scielo, Bireme, Banco Nacional de Teses. Foram utilizados os trabalhos com datas de 1995

a 2014. Muitos são os motivos para a compra de um veículo, como a ineficiência das políticas públicas de transporte e da compreensão da posse do automóvel como um símbolo de status, de ascensão social e de poder. 0 objetivo foi demonstrar as características do comportamento do consumidor, por meio de pesquisas já realizadas. Fica evidente que existe uma mudança na significação da posse do veículo com o seu uso nas vias. A psicologia centra-se nas questões relativas ao status do veículo e deste como objeto de poder. A comunicação preocupa-se com motivadores de consumo e os desdobramentos necessários aos fabricantes e revendedores para que fidelizem seus clientes e maximizem suas vendas.

\section{PALAVRAS-CHAVE}

psicologia do consumidor automóveis comportamento
This paper deals with the car consumers behavior. Search was performed by electronic means in the articles, dissertations and theses using Internet tools like, Scielo, Bireme, National Thesis Database. Were used works found with dates from 1995 to 2014. Many are the reasons for buying a vehicle, such as the inefficiency of public transport policies and understanding of automobile ownership as a status symbol of social mobility and power. The objective of this research is to demonstrate the characteristics of consumer behavior of cars in Brazil, through previous studies. Is evident that there is a change in the significance of vehicle ownership with its use on roads. Psychology focuses a lot on matters concerning the status of the vehicle and the object of this power. Communication is more concerned with the drivers of consumption and the developments necessary for manufacturers and dealers to maintain your customers and maximize your sales.

KEY WORDS

consumers psychology

car

behavior 


\section{INTRODUÇÃo}

Nos dias atuais, cada vez mais tem crescido o consumo dessa categoria de bem móvel, motivada pela estabilidade econômica presente no Brasil desde a segunda metade da década de 1990, com a implantação do Plano Real, sendo esse um programa brasileiro que objetivou a estabilização e as reformas econômicas, iniciado com a publicação da Medida Provisória n. 482, de 28 de abril de 1994, então convertida na Lei n. 8.880, de 27 de maio de 1994.

É intrigante perceber que a frota de veículos no Brasil tem se aproximado muito de uma unidade por pessoa, elevando esse objeto ao patamar de bem de uso individual. É fato que existem muitos motivos para a compra de um veículo, como a ineficiência das políticas públicas de transporte e da compreensão da posse do automóvel como um símbolo de status, de ascensão social e de poder. Muitas outras razões, inclusive econômicas, levam à compra de um veículo. 0 objetivo deste projeto é conhecer as características do comportamento do consumidor de automóveis no Brasil, por meio de pesquisas já realizadas. Acredita-se ser extremamente importante saber por que as pessoas compram seus automóveis e que tipos de características são fundamentais para gerar esse tipo de comportamento. Essa compra possivelmente venha a reduzir as dificuldades existentes para os usuários de transporte público, passando a desenvolver um novo tipo de interação com a cidade e de novos comportamentos de consumo ligados ao veículo, como a compra de combustíveis, lubrificantes, peças, dentre outros. É interessante pensar também no veículo como objeto de status, que levaria, para outro patamar social, a representação de seu possuidor.

O comportamento do consumidor de automóveis é um tema que apresenta pouco estudo e que reflete muito das características culturais, econômicas da população. 0 entendimento do comportamento do consumidor é fundamental para elucidar 
o perfil de consumo de um dos setores que mais crescem, e que tratam de um objeto que está intimamente ligado com o status e poder nos dias atuais. 0 automóvel enquanto objeto de consumo traz, nos argumentos que são utilizados para a sua venda, as raízes dos desejos e do comportamento posterior do consumidor, que não adquire somente um meio de transporte particular, mas o considera uma conquista, um estilo de vida, um acesso a uma classe especial. É preciso entender psicologicamente quais os implicadores nas escolhas, componentes familiares, de gênero, de classe socioeconômica, entre outros. Existem mais fatores ligados a essa escolha do que imaginam conscientemente os próprios consumidores, fazendo com que seja fundamental elucidar esses mecanismos de consumo.

\section{PERCURSO METODOLÓGICO}

0 presente artigo foi desenvolvido com o objetivo de conhecer as principais características do comportamento dos consumidores de automóveis no Brasil, por meio de uma pesquisa bibliográfica sobre o comportamento do consumidor de automóveis. Após a definição do tema a ser pesquisado, foram definidas as palavras chave para a realização de levantamento bibliográfico, buscando-se delinear o conhecimento existente a respeito do assunto, nos artigos de pesquisa publicados em revistas nacionais, bem como teses e dissertações sobre o assunto, considerando também indicações bibliográficas encontradas nas referências dessas obras. As palavras chave adotadas foram: comportamento do consumidor, psicologia do consumidor, automóveis.

Foi utilizada a pesquisa por meio eletrônico (Internet) de artigos, dissertações e teses por meio de ferramentas como o Google Escolar, Scielo, Bireme, Banco Nacional de Teses. Serão utilizados os trabalhos encontrados com datas de 1995 a 2014, para que a pesquisa utilize referenciais relativos ao período de 
estabilidade econômica proporcionada pelo Plano Real e que é referente ao bom momento vivido pela indústria automobilística nacional, bem como materiais de pesquisas recentes, mais atualizadas e contemporâneas.

Após o levantamento das obras existentes nessas bases a partir das palavras chave, foram descartadas aquelas que fugiam ao âmbito definido. Os materiais selecionados foram objeto de leitura e fichamento dos pesquisadores, que destacam as principais contribuições encontradas segundo o interesse desta pesquisa, articulando-as de modo a contextualizar e justificar sua realização, além de subsidiar a posterior análise de dados.

Posteriormente ao levantamento e revisão bibliográfica para base de um estudo empírico, pretendeu-se, dentre outras discussões, entender as razões que levam à compra dos automóveis e que tipos de fatores são preponderantes e se encontram presentes nas obras pesquisadas. Os dados obtidos foram analisados através de comparação de fatores apontados pelos autores como diferenciais para esse tipo de consumo.

\section{COMPORTAMENTO DO CONSUMIDOR}

O estudo do comportamento do consumidor é imprescindível para as ações de mercado. É preciso saber o que as pessoas precisam, o que as agrada para, então, conseguir fazer com que comprem algo. 0 marketing fundamentalmente precisa saber sobre os consumidores, para que o desenvolvimento, a produção e a comercialização de produtos atinjam seus objetivos. Os desejos, necessidades e motivações das pessoas precisam ser profundamente conhecidos para que se possa ter um estudo amplo e profundo sobre o que denomina-se de comportamento do consumidor (SAMARA; MORSCH, 2005).

Os conhecimentos envolvidos ultrapassam o marketing, trazendo também conhecimentos da psicologia, antropologia, socio- 
logia, administração, comunicação dentre outros. 0 consumidor é a razão de tudo, é o rei, é para ele, seja um indivíduo ou um grupo, que as ações são direcionadas. Sempre são levadas em consideração suas ações expressas no ambiente, seus comportamentos, mais é preciso observar mais do que isso; é preciso conhecer suas motivações, os eliciadores de seus comportamentos, os desejos que se quer satisfazer.

Para Spector (2012), Abraham Maslow (1908-1970), em A theory of human motivation (1943), já dizia que para que o ser humano tivesse saúde física e psicológica era preciso satisfazer as suas necessidades. De acordo com Maslow, eles possuem necessidades físicas, sociais e psicológicas que precisam ser satisfeitas ao longo da jornada. Dessa forma, pode-se entender que o comportamento expresso no ambiente é somente uma demonstração da busca da satisfação dessas necessidades, aquilo que aparece para o mundo, a ponta do iceberg.

Desse modo, fica bastante evidente que os produtos e serviços existentes no mercado precisam vir ao encontro dessas necessidades. Essa identificação faz todo o sentido quando se vê que as campanhas dos produtos geram uma relação profunda com seus consumidores, que transcende a posse do produto e que atinge, de maneira muito própria, necessidades internas, possibilitando o sanar de buscas e o preenchimento de lacunas existentes afetivamente em seu interior. É o envolvimento psicológico da posse, da realização, da resolução de um conflito (SAMARA; MORSCH, 2005).

Partindo desse ponto de que existem relações muito mais profundas envolvidas no que parece ser uma simples compra, e as pessoas consomem o tempo todo, ou seja, toda vez que existe uma prática de consumo existe alguém estudando como e por que o processo aconteceu e quais os seus reflexos, ou por que não aconteceu o que se esperava.

Giglio (2010) assevera que a maioria das teorias que tentam explicar o comportamento do consumidor são teorias raciona- 
listas, enfocando a capacidade de raciocínio e consciência do ser humano. Essas linhas de pensamento baseiam-se na teoria da consciência, muito presente no final do século XIX. Isso implica dizer que segundo essas teorias, os seres humanos seriam conscientes de suas ações e necessidades e as controlariam conforme sua vontade. As teorias são bastante difundidas e conhecidas, como as Teorias econômicas que se baseiam principalmente no fator da renda e sua relação com tipos e categorias de produtos, a Teoria de avaliação de risco e decisão, que se baseia fundamentalmente na análise do risco realizada pelo indivíduo para a execução daquela ação, ou seja, sua possibilidade de sucesso ou não levando em consideração fatores psicológicos e financeiros.

0 processo racional então compara o homem a uma máquina, que precisa comprar o que é necessário, pelo menor preço, com a melhor qualidade e condição. Essas teorias têm uma grande aceitação no meio do marketing, pois são muito fáceis de aplicar e de mensurar resultados, sendo simples e diretas.

Porém, Giglio (2010) expõe que existem críticas a essas teorias, pois elas desprezariam o lado subjetivo do comportamento e se concentrariam somente nas questões numéricas, trabalhando de uma maneira cartesiana e reducionista do comportamento humano. Esse menosprezar do lado subjetivo pode conduzir a enganos quando se pensa somente em pesquisas numéricas e objetivas, pois despreza a relação sentimental de satisfação que existe na relação de consumo, com um determinado produto ou marca quando se fala em satisfação, por exemplo, esta pode ser altamente diferente levando em conta fatores subjetivos de significação. Existe ainda um outro ponto da crítica a essas teorias, a de que não poderiam ser cientificamente comprovadas a consciência das necessidades pelo ser humano e o conhecimento dos caminhos para a sua solução.

Samara e Morsch (2005) citam o trabalho de Ernest Dichter (1907-1991), em The strategy of desire (1960), como um abridor 
de caminhos dentro da compreensão dos consumidores. Seus trabalhos trouxeram às empresas a ideia de que nem sempre o consumidor está consciente de suas decisões de consumo. Baseando-se em técnicas psicanalíticas de Sigmund Freud (18561939), Dichter conseguiu revelar motivações ocultas e subjetivas dos consumidores. Entrou em cena a pesquisa qualitativa, dando ênfase a ideias novas em relação a campanhas promocionais. Uma maneira de se perceber isso é justamente com uma técnica de produção de sentido, tal como quando perguntamos a um grupo que adjetivos estão relacionados a um produto como chocolate, por exemplo. Das respostas dadas, é possível extrair adjetivos que componham o material de campanha de uma marca de chocolate, que certamente encontrará eco nas respostas de consumo das pessoas.

Giglio (2010) traz então outra categoria de teorias para o consumo, as teorias motivacionais do comportamento do consumidor. Dentre elas se destacam as contribuições de estudiosos com Sigmund Freud, Carl Rogers (1902-1987) e Abraham Maslow.

Para Freud, afirma Giglio (2010), as pessoas não conhecem os seus desejos verdadeiros, pois são guiadas na maior parte de suas ações pelo inconsciente. Muitos trabalhos realizados na área de comportamento do consumidor tendo como ênfase as teorias freudianas colocaram em xeque as teorias racionais, até então dominantes nesse cenário de entender o consumo. A fé na consciência e na razão foi terrivelmente abalada depois dos estudos de Freud, trazendo a noção de que a consciência é subordinada ao inconsciente. Uma frase que ilustra bem o pensamento freudiano é dizer que nós, seres humanos, não somos senhores da própria casa. Essa realidade tem feito com que muitos profissionais do marketing aleguem várias causas inconscientes no que diz respeito ao consumo. Vale lembrar que as teorias freudianas são muito menos objetivas do que as teorias racionais com seus questionários, por exemplo, tendo dificuldade em quantificar comportamentos 
e motivações. Para o estudo com teorias motivacionais de base psicanalítica, precisa-se entender o sujeito como ser histórico, sendo seu presente o reflexo de suas vivências anteriores. Afirmam Samara e Morsch (2005) que, pensando assim, é preciso atentar-se para as raízes do indivíduo e suas sementes, para entender as suas flores e frutos.

Adentrando na teoria freudiana, pode-se dizer que o consumo de um automóvel estaria ligado, por exemplo, à satisfação de desejos inconscientes de poder que poderiam resultar em sucesso afetivo num relacionamento com o seu par romântico.

De acordo com Giglio (2010), outro expoente muito importante das teorias motivacionais do consumo seria Abraham Maslow. Ele desenvolveu uma teoria de que as pessoas teriam cinco planos básicos em sua vida que guiariam suas ações, tendo a satisfação das necessidades fisiológicas o primeiro deles seguidas pelas necessidades de segurança, afeto, relacionamento e autorrealização. Maslow acreditava que a felicidade total era a realização plena dos cinco planos, mas que somente um por cento das pessoas chegariam a essa condição. Ele não escrevia especificamente sobre o consumo, como Freud também não o fez, tampouco criou uma teoria de degraus a serem galgados ao longo da vida, já que postulava que os níveis eram independentes uns dos outros. Mas vale ressaltar que haverá uma concentração maior de energia em necessidades de relacionamento, por exemplo, quando as necessidades fisiológicas estiverem bem atendidas.

As necessidades fisiológicas são básicas, pois se relacionam com fome, sede e sono. As necessidades de segurança física e psicológica trabalham muito com experiências repetitivas e seguras, ficando preferencialmente em sua zona de conforto com produtos conhecidos e não se arriscando com novidades. Um produto que é exemplo dos que se apresentam nessa esfera é a poupança, que visa garantir segurança física em caso de necessidade, porém com risco baixo de prejuízo (GIGLIO, 2010). 
As necessidades de afeto e pertencimento a grupos, de se sentir amado e sexualmente seguro podem ser representadas por produtos como cerveja, cigarro e perfumes por exemplo. As necessidades de status e de estima referem-se a ser reconhecido pelos outros e até de ter suas qualidades de inteligência, força, competência. Produtos que costumam explorar essas necessidades são carros de luxo e joias, que muitas vezes se colocam em seus anúncios como símbolos de sucesso, riqueza, poder e estilo (SAMARA; MORSCH, 2005).

Martin (2009) assevera que, de acordo com as teorias cognitivas do comportamento, têm-se dois tipos de ações em mente, executiva e habitual. A mente executiva é guiada pelo consciente, que pensa que está no controle, mas na verdade o consumo é controlado pela mente habitual que é guiada pelo inconsciente. A mente executiva só consegue se concentrar em uma ação de cada vez e, quando vive uma experiência satisfatória ou não, delega uma execução futura de uma operação semelhante à mente habitual, deixando de ter seu controle. As situações novas ativam e focalizam a mente executiva.

A maioria dos clientes segue sempre a mesma rota dentro da loja, como se seguisse um caminho invisível sob seus pés. Isso libera a mente para pensar nas compras, decidir o que será servido no jantar ou ponderar sobre os mistérios do universo. Esta estratégia de eficiência se aplica a qualquer categoria em que as marcas sirvam de indutoras para automatizar a decisão de compra. A mente executiva está constantemente transferindo decisões para a mente habitual exatamente deste modo. (MARTIN, 2009, p. 15).

As mentes executiva e habitual estão em constante interação, interpretando o ambiente e reagindo numa complexa e ensaiada dança. Os maiores sucessos do marketing estão ligados à mente habitual, como a Coca-Cola, por exemplo, que pode ser reconhecida mesmo se somente $5 \%$ de sua logomarca estiver visível. Esta logo não sofreu modificações desde 1885, com sua caligrafia especial, tornando-se assim a marca mais valiosa do mundo. A mente 
executiva é um empregado, e a mente habitual é o alto executivo. 0 poder da mente habitual tem algumas implicações como, por exemplo, as empresas devem concentrar-se no comportamento do consumidor que é repetitivo e visível, e não em crenças, pois são transitórias.

Outro ponto deve ser o de não fazer o consumidor pensar conscientemente sobre seu produto, mas manter o comportamento de compra no automático. Para fazer o cliente de seu concorrente mudar o seu hábito, deve-se fazê-lo pensar conscientemente sobre o produto de seu concorrente para que ele pense em mudar, porém, quanto mais forte for o hábito, mais difícil será trazê-lo à consciência para refletir (MARTIN, 2009).

Canclini (2009) diz que as transformações pela industrialização, na produção e acesso à cultura, na globalização e na digitalização se apresentam nos hábitos dos jovens. Estudar o comportamento dos jovens seria uma maneira de entender para onde o mundo caminha e descobrir informações inovadoras sobre quais os comportamentos que estão presentes. Muitos jovens quando consomem músicas, roupas e filmes recorrem a meios ilegais. Os meios informais de venda têm muitas vezes satisfeito mais desejos que shoppings e espaços tradicionais de compras. Os jovens estão se informando muito menos por jornais e mais por meios eletrônicos, tem tido menos interesses por livros também. Essas modificações nos padrões de consumo são novos desafios, para uma psicologia que seja capaz de responder quem são esses jovens, qual o futuro do consumo e quais os desafios no entendimento dos novos consumidores.

\section{AUTOMÓVEL}

Vasconcelos (2005) assevera que, conforme a humanidade foi se desenvolvendo, os seres humanos foram se agrupando nos núcleos urbanos e desenvolvendo estruturas de transporte. No 
começo, era suficiente o deslocamento com as próprias pernas, mas, conforme o trabalho, as necessidades e as construções foram se tornado complexas, iniciou-se a utilização de tecnologias. Primeiro com a domesticação e uso de animais, para carregar pessoas e objetos e depois com o desenvolvimento da roda, estava aberto o caminho para a interação entre os núcleos urbanos, mas também, o princípio do desenvolvimento do transporte individual.

No final do século XIX e início do século XX, os automóveis, antes raros nas cidades, começaram a fazer parte de seu panorama. Dessa forma, o veículo passou a ser um objeto de desejo, que passou a integrar a lista dos desejos dos cidadãos. Com a crescente industrialização e o fordismo, esse desejo tornou-se cada vez mais forte e mais alcançável, para fins comerciais e familiares (OKUBARO, 2001).

DaMatta (2012) indica que inicialmente a busca pelo automóvel, bem como pelas outras tecnologias de transporte, deveu-se às ocupações dos territórios e à necessidade de locomoção. Porém a utilização do automóvel atingiu um outro patamar de uso exclusivo e pessoal além de passar a ser utilizado como um objeto de poder. Esse processo foi evoluindo até que se chegou ao mar de conflitos existentes nas cidades tendo como pivô o veículo automotor. A impressão que se tem é de que as pessoas, muitas vezes, são incapazes de imaginar o seu cotidiano sem o uso desse objeto. E cada vez mais vão se integrando opções de luxo e sofisticação a um objeto que deveria somente ser um meio de transporte, redirecionando seu status para um nível alucinante e alienante.

0 veículo é peça fundamental no sistema complexo do trânsito, e, como coloca Rozestraten (2006, p. 7), “[...] cada veículo é massa em movimento. Como tal obedece às leis da física de movimento, de inércia, de forças centrípetas e centrífugas [...]”.

Os motivos que levam os indivíduos a circularem nas vias urbanas são vários e mudam conforme suas necessidades que podem variar de uma hora para outra, como o homem que sai para 
o trabalho de manhã. Antes ele tem que levar o filho na escola, sua necessidade nesse momento é de levar seu filho de forma mais rápida e segura, a fim de que possa chegar no horário no seu emprego. Para isso ele mobiliza toda uma logística para que suas metas sejam alcançadas (VASCONCELOS, 1992).

Dessa forma, Vasconcelos (1992) explica que o "homem" traça uma lista de tarefas e objetivos a cumprir a fim de ter a satisfação total, porém, quando deixa seu filho na escola, sua necessidade muda; agora precisa chegar ao emprego em tempo hábil e encontrar um espaço para estacionar o carro. Já quando sai para seu almoço, se por um acaso for almoçar com seus colegas de trabalho, sua necessidade muda.

Ele sai andando pela calçada, também busca um restaurante próximo e de fácil acesso, necessita agora de uma boa mobilidade nas calçadas com sinais e semáforos de trânsito. No final do dia, necessita se locomover para buscar o filho na escola, encontrar um lugar perto da saída do colégio e, finalmente, ir para casa tendo as vias um acesso rápido e seguro. Todos os indivíduos têm necessidades distintas, mas todos querem chegar ou ir a algum lugar da melhor maneira possível.

Porém existem conflitos nessas viagens: "O primeiro deles é o conflito físico, mais conhecido, de disputa pelo espaço, como no caso de dois veículos que se aproximam ao mesmo tempo de um cruzamento, ou de um pedestre que deseja passar entre vários veículos em movimento. Esse tipo de conflito é o mais aparente no trânsito, mas não é o único: existe outro, a que chamo de político, pois reflete os interesses das pessoas no trânsito, que por sua vez estão ligados a sua posição no processo produtivo da cidade". (VASCONCELOS, 2005, p. 13).

A convivência no espaço público se constrói a cada instante, precisando sempre da ordenação para evitar que os conflitos cheguem a um grau superlativo, no qual o maior se sobreponha sobre o menor. 


\subsection{Automóvel e status}

Atualmente, segundo Carvalho e Prado (2005), o automóvel tem papel importante para a sociedade, que vai além de sua utilidade como meio de locomoção. As pessoas têm estabelecido no campo psicológico, uma relação com seu carro, ou seja, o condutor idealiza e projeta no veículo, a força, o status e o poder, que estão ligados à necessidade de serem aceitos perante a sociedade como alguém com importância e valor.

Essa ligação entre veículo e status é acentuada, pois o modelo de mobilidade escolhido é o automóvel como principal transporte. A posse do veículo representa, além de status, poder. Conduzir um veículo tem sido erroneamente considerado por uma grande parte das pessoas, como a possibilidade de ser independente, de ser "dono do próprio destino", por meio do domínio do espaço e da velocidade (DAMATTA, 2012).

A pesquisa realizada por Corassa (2003) com condutores, elucidou os significados atribuídos ao automóvel e quais os valores culturais que permeiam a relação em motorista e automóvel. Concluiu-se que o carro é visto como parte da casa, sua extensão, portanto, um espaço de proteção física, psicológica, abrigo da chuva e frio, suprindo muitas das necessidades humanas.

0 sentimento e a sensação de liberdade podem ser vividos pelos motoristas ao dirigir. 0 carro propicia prazer, no entanto esse sentimento também pode liberar sentimentos reprimidos, como a agressividade e a impulsividade (CARVALHO; PRADO, 2005).

O significado atribuído ao automóvel é ambíguo, pois, como objeto de poder, pode tanto ser instrumento de expressão de liberdade e autonomia, como de descarga de agressividade e tensão. Essa ambiguidade torna o conduzir desgastante, pois a necessidade de manter o equilíbrio psicológico no trânsito exige autoconhecimento nas mais diferentes situações (CORASSA, 2003). 
A representação social sobre carro encontra-se intimamente ligada aos valores, fantasias e costumes culturais da sociedade. Isto estaria demonstrado no fato de que os homens, quando crianças, ganham carrinhos de brinquedo, o que proporciona uma familiaridade com o mundo dos automóveis (CARVALHO; PRADO, 2005).

Gorz (2005) explica que, quando o automóvel foi inventado, tinha a finalidade de proporcionar aos burgueses um privilégio inédito: circular pelas ruas e estradas mais rapidamente que todos os demais. Isso trouxe uma realidade sequer imaginada em sonho, pois as carruagens, fossem de ricos ou pobres, circulavam relativamente com a mesma velocidade. Os trens eram velozes, mas levavam gente de todas as classes ao mesmo tempo e na mesma velocidade. Até final do século XIX e o início do século $\mathrm{XX}$, a elite não conseguia ainda se diferenciar do povo pelo domínio da velocidade. 0 automóvel mudou esta realidade e levou a burguesia a estabelecer mais esse distanciamento em relação aos demais.

Aparentemente o automóvel confere ao seu usuário uma independência ilimitada, mas diferentemente dos meios de transporte utilizados anteriormente, agora ele depende de outros, especialistas na manutenção e troca de peças de sua máquina. Ao contrário dos meios de locomoção anteriores, o motorista deixa o papel de possuidor e dono, para ocupar o de usuário e consumidor, mesmo sendo proprietário do veículo.

Os magnatas do petróleo então perceberam o tamanho do negócio que se propunha, como haveria tantos motoristas como o número de famílias, teriam em cada família um consumidor. 0 sonho capitalista estava em curso, todos passariam a depender de uma única indústria fornecedora.

A persuasão para a venda de automóveis seria pouca, somente baixand o o preço. As pessoas se debruçariam a comprá-lo, acreditando que teriam o mesmo privilégio de se deslocar como os senhores e os burgueses e mais rápido que as pessoas comuns, 
teriam agora destaque. Dessa forma, na sociedade do automóvel o privilégio da elite estava colocado ao alcance de outros (GORZ, 2005).

No pós-Segunda Guerra, com a implantação do estado de bem-estar nos Estados Unidos, o automóvel, a grande vedete do fordismo, passou a figurar como uma das necessidades primeiras das famílias, o maior bem consumido após a casa própria, relativo a vários meses de salário. Ficou dependente da produção do carro uma série de indústrias, como a da borracha, aço, plástico, petróleo, materiais elétricos dentre outros. Isso passou a ser tão sério, que a produção da automóvel tornou-se um indicador econômico nos Estados Unidos, surgindo a expressão "quando a General Motors espirra a América fica resfriada" (AUFHEBEN, 2005).

Fica evidenciada a proporção que a presença do automóvel representa na esfera do consumo, fazendo com que seja muito importante conhecer que conceitos mais se compram junto com ele. Control (2005) cita um anúncio do Mazda Mx-5 como referência do atrelado à compra do automóvel, certamente muito mais do que um simples meio de transporte:

$0 \mathrm{Mx}-5$ distingue-se na sua capacidade de envolver o motorista em cada ação, de modo que você logo sinta que é apenas uma , de uma quantidade de partes que se movimentam, tudo em total harmonia. Troque a marcha: a maneira que ela se move através do seu caminho perfeito é uma revelação. (CONTROL, 2005, p. 104).

Furtado (2010) esclarece que também houve ações do governo brasileiro, ações cirúrgicas e bastante eficientes, que foi a redução do Imposto sobre Produtos Industrializados (IPI) para a produção de automóveis. 0 governo brasileiro pegou um setor que é um setor central na economia brasileira, justamente porque a cadeia produtiva das montadoras é uma cadeia produtiva extensa. Ela vai desde a produção do automóvel nas montadoras, Volkswagen, General Motors, Fiat, dentre outros, até a produção 
de carvão. Portanto garantir a venda dos veículos produzidos garante emprego, e garantir emprego garante consumo da produção nacional. Garantia de mercado interno.

0 automóvel então é mais do que um simples bem de consumo relativo ao poder individual que representa para o usuário, mas também uma indústria que financia o lucro de diversos países, jogando os consumidores para o seu consumo como forma de fazer a máquina econômica funcionar (FURTADO, 2010).

\section{COMPORTAMENTO DO CONSUMIDOR DE AUTOMÓVEIS}

Desde o início dos anos 1990, o mercado de consumo de automóveis no Brasil tem se tornado cada vez mais competitivo. Durante o governo do presidente Fernando Collor de Mello - de 15 de março de 1990 a 29 de dezembro de 1992 - houve uma mudança na política com as montadoras de automóveis, permitindo-se a entrada no país de veículos importados, gerando um novo panorama nesse mercado. Atualmente temos cerca de 50 montadoras no país responsáveis pela fabricação de veículos automotores. Dessa forma, o mercado brasileiro se desconcentrou das quatro grandes marcas que antes reinavam no mercado interno, Chevrolet, Ford, Fiat e Volkswagen. 0 desejo da compra do automóvel novo é praticamente um sonho, que vivia antes nas classes A e B e agora tem invadido também a classe C (SAMPAIO et al., 2004).

A necessidade de aquisição do automóvel, levando em consideração a hierarquia das necessidades de Maslow, se encontraria no nível de estima, pois faz referência ao status quo e ao prestígio. Em relação ao processo de decisão de compra, Mattar (1982) esclarece que esse ocorre em cinco fases, sendo a primeira a de reconhecimento do problema; a segunda, a da procura de soluções; a terceira, de avaliação das alternativas, a quarta reside no processo de compra; e a última; no comportamento e experiência de pós-compra. 
Num estudo de Sampaio et al. (2004), realizado com 43 pessoas que acabaram de comprar um carro novo, as causas mais apontadas para a compra de um carro novo são o lançamento de um modelo novo (32,6\%), o fato de o carro anterior estar velho e ruim $(20,9 \%)$ e a procura de diminuir a distância entre o preço do veículo usado e o do novo (41,9\%), mas também aparece a necessidade social de aquisição com uma parte dos entrevistados $(11,6 \%)$ informando que a posição social ou o cargo que ocupam trazem a necessidade de um veículo novo. Entre as fontes consultadas para obter informações sobre o produto, as que mais apareceram foram a consulta entre parentes e amigos (46,5\%), revistas especializadas $(32,6 \%)$ e propagandas na televisão $(27,9 \%)$. Na avaliação de alternativas, 64\% dos entrevistados afirmam visitar mais de uma loja antes de comprar, e os demais (36\%) visitam apenas uma loja. 0 atendimento mostra-se como item principal na opção de compra sendo valorizado pela maioria da amostra $(55,8 \%)$. Os fatores que norteiam a compra de um automóvel zero quilômetro mais indicados foram a qualidade do produto $(81,4 \%)$ e o preço $(72,1 \%)$. Já em relação à forma de pagamento, a maioria (48,9\%) prefere fazer a prazo e uma parte considerável da amostra (43\%) prefere fazer a vista. Em relação a comparem veículos da mesma marca, a grande maioria dos entrevistados $(72,2 \%)$ pretende continuar comprando assim.

Em pesquisa realizada por Pires e Marchetti (2000), sobressaem as preocupações financeiras dos consumidores de automóveis, tendo grande importância fatores como manutenção e a relação de quilômetros rodados por litro de combustível e a consequente economia, o preço, as condições de pagamento e a garantia de um bom preço de revenda do automóvel depois de usado.

Em pesquisa desenvolvida por Silva, Farias e Cerqueira (2012), sobre o consumo de veículos por pessoas de baixa renda, elucidou-se que a fonte de informação que mais influencia tanto 
nas classes $\mathrm{C}$ e D, como na E são as informações passadas por amigos e parentes. Na forma de aquisição, as classes D e E preferem fazer em sua maioria o uso do consórcio, o que implica uma espera maior pelo bem, mas um pagamento menor de juros. Em síntese, parece existir uma busca pela qualidade do produto, uma necessidade de um bom pós-compra e da presença da tecnologia no produto quando avaliadas as alternativas de aquisição.

Oliveira (2005) destaca em sua pesquisa as diferenças no consumo de automóveis entre homens e mulheres, sendo os homens mais preocupados com preço $(95,8 \%)$, valor de revenda $(95,8 \%)$ e marca $(91,6 \%)$, enquanto para as mulheres os atributos mais importantes são cor (100\%), direção hidráulica (95,8\%) e design (91,6\%), revelando uma boa diferença no perfil de compra entre os sexos. Aparecem ainda alguns pontos importantes como a informação de que as mulheres estão envolvidas na decisão da compra do carro em $87,5 \%$ dos casos e que, sobre informações, concorrência e facilitadores de vendas, 100 \% dos pesquisados afirmaram que os indivíduos do sexo masculino se destacam mais nesses aspectos. Em relação ao pós-compra, a maioria das mulheres $(79,2 \%)$ admite fazer uso do Serviço de Atendimento ao Consumidor, enquanto entre os homens o uso desse serviço é de apenas uma parte $(45,8 \%)$ dos consumidores.

Popcorn e Marigold (2003, p. 58) evidenciam o crescimento do papel da mulher como consumidora e influenciadora de consumo de automóveis "[...] as mulheres compram ou influenciam na aquisição de $80 \%$ de todas as mercadorias de consumo [...]". 0 automóvel, antes marcadamente símbolo masculino, está cada vez mais presente no universo feminino.

Em sua pesquisa com mulheres consumidoras de automóveis, Naves (2012, p. 94) aponta que:

[...] foi possível levantar que as aquisições de carros novos se efetivam como resultado de uma necessidade real de ter um meio de locomoção, que atenda às necessidades das consumidoras, se- 
jam para locomoção para o trabalho, para levar os filhos à escola ou mesmo lazer em ocasiões onde apenas a mãe está presente com filhos ou sozinha. A probabilidade de aquisição por status não foi apontada pelas entrevistadas, identificando a primeira etapa do processo decisório do consumidor, o reconhecimento da necessidade.

Naves (2012) esclarece que a pesquisa demonstra que as mulheres que adquirem um carro novo, levam em conta aspectos como a praticidade, benefícios e vantagens que o carro zero quilômetro oferece como a garantia de não precisar se preocupar com manutenções dispendiosas durante um período razoável.

As cinco características observadas como destaques da aquisição de veículos automotores novos por mulheres são a capacidade financeira de pagar o bem adquirido, sem prejudicar o orçamento familiar, a qualidade do produto, sendo inclusive mais exigentes que os homens nesse quesito, a segurança, exigindo o maior número possível de itens nesse sentido, o design moderno e a cor do veículo que devem ser de seu total agrado e finalizando com as características técnicas sobre as quais as mulheres têm pouco conhecimento, mas que podem ser decisivas na hora da compra, apoiando-se em informações de diversas fontes como maridos, amigos e vendedores (NAVES, 2012).

Muitas outras pessoas influenciam o comportamento de compra, como esclarecem Churchill Jr. e Peter (2003) sobre o papel da família, amigos, confrarias, e colegas de trabalho. Por meio de opiniões, vivências e testemunhos, ocorre indiretamente uma influência, devido ao convívio e as impressões que são passadas referentes a certos produtos, marcas e serviços.

Para Severiano (2007), o fetiche existente na mercadoria automóvel teria como mecanismo deixar esparsas as relações sociais de trabalho, e também sua posse passaria a incorporar valores imateriais e simbólicos que trazem alienação da subjetividade, mascarados pela encarnação de qualidades subjetivas como a felicidade, poder, segurança e autonomia. 
Morais, Pascual e Severiano (2011) acreditam que a necessidade de aquisição do automóvel e da valorização desta aquisição como paixão, respondendo a slogans como "apaixonado por carro como todo brasileiro" é um produto de marketing oferecido pela indústria cultural e não emanado da cultura popular, que é feito justamente com a intenção de aumentar o consumo de automóveis, combustíveis e outros produtos agregados do setor.

Para Engel, Blackwell e Miniard (2000), o status também seria um dos grandes impulsionadores da compra, transferindo, de certa forma, do automóvel como um item caro, para seu possuidor, muitas características que são buscadas através do consumo e que cotidianamente povoam os slogans das montadoras, como estilo, elegância, potência, luxo, exclusividade. Seria como se o possuidor desse item apresentasse uma diferenciação dos demais, sendo digno de admiração, de diferenciação do comum.

Pode-se entender claramente, no conceito de Karsaklian (2000, p. 11), "Essas preferências estarão diretamente relacionadas ao auto-conceito : o consumidor tenderá a escolher um produto que corresponda ao conceito que ele tem ou que gostaria de ter de si [...]", o objeto seria, dessa forma, um acoplador de características subjetivas.

Em complementação, entende-se como o meio e a personalidade também influenciam a compra, como expõem Engel, Blackwell e Miniard (2000, p. 50-51): “O que leva as pessoas a se decidirem por um determinado produto vem de sua personalidade, de seu estilo de vida e das forças sociais [...]". Dentro desse estilo de vida, estariam categorias de produtos premium, por exemplo, mais adequados aos altos níveis sociais.

O estilo de vida, padrão, grupo social, papel social podem dizer muito sobre o status e o consumo:

[...] toda função social ou papel social desempenhado por um indivíduo leva associado certo status. 0 status é uma posição socialmente classificada. 0 papel social é o padrão de compor- 
tamento que se espera de pessoas que ocupam um determinado status. A estrutura social é um sistema organizado de papéis ou funções sociais, que definem as relações entre grupos e indivíduos. (SOLOMON, 2002, p. 124).

Torres e Allen (2009) observam que cada vez mais a ligação entre a satisfação de valores culturais e o comportamento de consumo devem ser estudadas. Existe a necessidade de que o marketing se ocupe também das relações culturais e das práticas de consumo, enfatizando os comportamentos preditores da compra. Não deve ser considerado somente o momento do consumo, mas também aquilo que acontece anteriormente, seus eliciadores.

Dittmar (1992) enfoca que a significação em nível simbólico de um objeto é carregado de experiências sociais, que levam a uma subjetivação do produto, em sua interiorização. Existem atributos intangíveis e que estão imersos culturalmente, respondendo a imagens e simbolismos. 0 processo de compra está carregado de escolhas conscientes entre alternativas variadas.

0 modelo de duas rotas de Allen $(2000,2001)$ e Allen, NG e Wilson (2002) está em testes com uma grande gama de produtos como carros, óculos de sol e comida além de serviços e viagens de turismo. Os resultados mostram que o caminho em que os valores humanos influenciam a escolha de um produto apresenta algumas condições quando este tem uma função instrumental: significado utilitário de produto e julgamento passo a passo. Se o produto tem uma significação simbólica, o consumidor julga afetivamente, e os valores humanos influenciam diretamente a compra, suplantando os aspectos tangíveis do produto.

\section{CONSIDERAÇÕES FINAIS}

Depois de realizadas leituras mais aprofundadas sobre o assunto, fica evidente que existe uma mudança na significação da posse do veículo com o seu uso nas vias. A psicologia centra- 
-se muito nas questões relativas ao status do veículo e deste como objeto de poder. A comunicação preocupa-se mais com os motivadores de consumo e com os desdobramentos necessários aos fabricantes e revendedores para que fidelizem seus clientes e maximizem suas vendas.

Com o uso nas ruas, percebe-se que, depois de adquirido, o automóvel se torna uma ferramenta de domínio do espaço público, de sobressair sobre o próximo, um instrumento de diferenciação. É extremamente importante que sejam desenvolvidas pesquisas que estudem a produção de sentido da posse e do uso do automóvel, bem como da sua aquisição; aue deem conta de esclarecer as representações sociais existentes acerca desse objeto cada vez mais individual nas cidades. Seria essa mudança fruto da indústria cultural? Ou a convivência em meio ao coletivo seria a grande responsável pelo uso e o papel que atribuímos ao veículo automotor? É preciso lembrar que o carro é um objeto inanimado e que as características intangíveis que lhe são atribuídas são fruto da cultura. Qual o limite para o exercício desse poder? Qual o preço a pagar por ele? O trânsito é ambiente de conflito. Isto está posto, é incontestável. Mas até aonde se vai para sobrepujar a própria vontade à do próximo? Até o limite de lhe tirar a vida. É o que se tem visto todos os dias. A incapacidade de mediar os conflitos e de viver o coletivo.

E isso tem sido demonstrado todos os dias nas escolas, nas empresas, nos supermercados, com a intolerância em ter que dar a vez ao outro, em dividir, em alternar o protagonismo. A diferença é que, no trânsito, têm-se utilizado armaduras brilhantes, velozes, potentes e confortáveis, adquiridas para ser instrumento de prazer e não meio de transporte. A cultura do transporte coletivo bem estruturado consegue mediar melhor essa convivência coletiva ao que parece. $\mathrm{O}$ individualismo no consumo dos automóveis legitima a experiência de sobrepujar-se sobre os demais, de sentir-se diferente, mais, premium. Mas vale lembrar que sem o outro não 
existe relação. 0 uso dos veículos no trânsito como ambiente social é uma demonstração de que o ser humano foge de suas raízes gregárias e passa a exercitar cada vez mais o biologismo da seleção natural. Como produto da própria indústria, passa a cumprir papel específico, quando deveria ser multideterminado. Que o ronco dos motores e o ruído das buzinas sejam mais que o som de um conflito, mas um alerta de que a colisão consigo mesmo está cada vez evidente.

\section{REFERÊNCIAS}

ALLEN, M. W. The attribute-mediation and product meaning approaches to the influences of human values on consumer choices. In: COLUMBUS, F. (Ed.). Advances in psychology research. Huntington, NY: Nova Science, 2000. v. 1, p. 31-76. Disponível em: <http://works.bepress.com/cgi/ viewcontent.cgi?article $=1003 \&$ context $=$ michael_allen1>. Acesso em: 5 dez. 2014.

A practical method for uncovering the direct and indirect relationships between human values and consumer purchases. Journal of Consumer Marketing, Bradford, v. 18, n. 2, p. 102-120, 2001.

ALLEN, M. W.; NG, S. H.; WILSON, M. A functional approach to instrumental and terminal values and the value-attitude-behaviour system of consumer choice. European Journal of Marketing, Bradford, v. 36, n. 1-2, p. 111-135, 2002.

AUFHEBEN. A importância do carro para a economia moderna. In: LUDD, N. (Org.). Apocalipse motorizado: a tirania do automóvel em um planeta poluído. São Paulo: Conrad, 2005. p. 83-102.

BRASIL. Presidência da República. Medida Provisória n. 482, de 28 de abril de 1994. Dispõe sobre o Programa de Estabilização Econômica, o Sistema Monetário Nacional, institui a Unidade Real de Valor (URV) e dá outras providências. Diário Oficial [da] República Federativa do Brasil, Brasília, DF, 29 abr. 1994a. Disponível em: <http://www. planalto.gov.br/ccivil_03/MPV/1990-1995/482.htm>. Acesso em: 4 dez. 2014. 
BRASIL. Presidência da República. Lei n. 8.880, de 27 de maio de 1994. Dispõe sobre o Programa de Estabilização Econômica e o Sistema Monetário Nacional, institui a Unidade Real de Valor (URV) e dá outras providências. Diário Oficial [da] República Federativa do Brasil, Brasília, DF, 15 maio 1994b. Disponível em: <http://www.planalto.gov.br/ ccivil_03/LEIS/L8880.htm>. Acesso em: 28 nov. 2014.

CANCLINI, N. G. Consumo, acesso e sociabilidade. Comunicação, Mídia e Consumo, São Paulo, v. 6, n. 16, p. 111-127, 2009.

CARVAlHO, R. C.; PRADO, M. M. Sem medo de dirigir. São José dos Campos, SP: Mirian, 2005.

CHURCHILL JR., G. A.; PETER, J. P. Marketing: criando valor para os clientes. Tradução de Cecília Camargo Bartalotti e Cid Knipel Moreira. São Paulo: Saraiva, 2003.

CONTROL, M. Acabem com todos os carros. In: LUDD, N. (Org.). Apocalipse motorizado: a tirania do automóvel em um planeta poluído. São Paulo: Conrad, 2005. p. 103-118.

CORASSA, N. Uso do carro como uma extensão da casa e os conflitos no trânsito. In: HOFFMAN, M. H.; CRUZ, R. M.; ALCHIERI, J. C. (Org.). Comportamento humano no trânsito. São Paulo: Casa do Psicólogo, 2003. p. 61-74.

DAMATTA. R. Fé em Deus e pé na tábua: ou como e porque o trânsito enlouquece no Brasil. São Paulo: Rocco, 2012.

DITTMAR, H. The social psychology of material possessions: to have is to be. New York: St. Martin's Press, 1992.

ENGEL, J. F.; BLACKWELL, R. D.; MINIARD, P. W. Comportamento do consumidor. Rio de Janeiro: LTC, 2000.

FURTADO, O. Espaço público: direito de todos. In: CONSELHO FEDERAL DE PSICOLOGIA. Psicologia e mobilidade: o espaço público como direito de todos. Brasília, DF, 2010. p. 27-40. Disponível em: <http://site.cfp.org. br/wp-content/uploads/2012/07/seminario_mobilidade_27_08_10. pdf>. Acesso em: 5 dez. 2014.

GIGLIO, E. M. O comportamento do consumidor. São Paulo: Cencage Learning, 2010. 
GORZ. A. A ideologia social do automóvel. In: LUDD, N. (Org.). Apocalipse motorizado: a tirania do automóvel em um planeta poluído. São Paulo: Conrad, 2005. p. 73-82.

KARSAKLIAN, E. Comportamento do consumidor. São Paulo: Atlas, 2000. MARTIN, N. Hábitos de consumo. Rio de Janeiro: Elsevier, 2009.

MATTAR, F. N. O comportamento do comprador de automóveis novos. Revista de Administração, São Paulo, v. 17, n. 3, p. 50-59, 1982. Disponível em: <http://www.spell.org.br/documentos/download/19281>. Acesso em: 5 dez. 2014.

MORAIS, R. C.; PASCUAL, J. C.; SEVERIANO, M. F. V. Apaixonados por carros como todo brasileiro" (?) - Reflexões frankfurteanas sobre a indústria cultural contemporânea. Estudos e Pesquisas em Psicologia, Rio de Janeiro, v. 11, n. 3, p. 873-897, 2011. Disponível em: <http://www.e-publicacoes.uerj.br/index.php/revispsi/article/ download/8341/6135>. Acesso em: 5 dez. 2014.

NAVES, F. V. R. A mulher e a decisão de compra de automóvel: propósitos e processos. 2012. 110 f. Dissertação (Mestrado em Administração) Faculdades Integradas de Pedro Leopoldo, Pedro Leopoldo, RS, 2012. Disponível em: <http://www.fpl.edu.br/2013/media/pdfs/mestrado/ dissertacoes_2012/dissertacao_fabiana_vieira_reis_naves_2012.pdf>. Acesso em: 5 dez. 2014.

OKUBARO, J. O automóvel, um condenado? São Paulo: SENAC, 2001.

OLIVEIRA, R. O. A atividade de vendas na era das relações: uma análise da percepção da força de vendas de automóvel no mercado de Santos X comportamento de compra de automóvel novo. eGesta: revista eletrônica de gestão de negócios, Santos, SP, v. 1, n. 2, p. 85105, 2005. Disponível em: <http://webcache.googleusercontent.com/ search?q=cache:6nh340arzQcJ:www.unisantos.br/mestrado/gestao/ egesta/artigos/36.pdf $+\& \mathrm{~cd}=1 \& \mathrm{hl}=\mathrm{pt}-\mathrm{BR} \& \mathrm{ct}=\mathrm{clnk} \& \mathrm{gl}=\mathrm{br}>$. Acesso em: 5 dez. 2014.

PIRES, V. C.; MARCHETTI, R. Z. Fatores influenciadores na escolha da fonte de informação na compra de automóveis novos: a importância da comunicação boca a boca. In: ENCONTRO ANUAL DA ASSOCIAÇÃO NACIONAL DE PROGRAMAS DE PÓS-GRADUAÇÃO EM 
ADMINISTRAÇÃO, 24., 2000, Florianópolis. Anais... Rio de Janeiro: Associação Nacional de Pós-Graduação e Pesquisa em Administração, 2000. p. 1-16. Disponível em: <http://www.anpad.org.br/diversos/ trabalhos/EnANPAD/enanpad_2000/MKT/2000_MKT300.pdf>. Acesso em: 5 dez. 2014.

POPCORN, F.; MARIGOLD, L. Público-alvo mulher: 8 verdades do marketing para conquistar a consumidora do futuro. Rio de Janeiro: Campus, 2003.

ROZESTRATEN, R. J. A. Psicologia do trânsito: conceitos e processos básicos. São Paulo: Editora Pedagógica e Universitária, 2006.

SAMARA, B.; MORSCH, M. A. Comportamento do consumidor: conceitos e casos. São Paulo: Prentice Hall, 2005.

SAMPAIO, D. et al. Um estudo comparativo sobre o comportamento do consumidor de automóveis novos. In: SEMINÁRIOS EM ADMINISTRAÇÃO FEA-USP, 7., 2004, São Paulo. Anais... São Paulo: Faculdade Estácio de Sá, 2004. Não paginado. Disponível em: <http://www.ead.fea.usp. br/Semead/7semead/paginas/artigos\%20recebidos/marketing/ MKT76_-_Um_Estudo_comparativo_do_comp_consumid.PDF $>$. Acesso em: 5 dez. 2014.

SEVERIANO, M. F. Narcisismo publicidade: uma análise psicossocial dos ideais de consumo na contemporaneidade. São Paulo: Annablume, 2007.

SILVA, A. B.; FARIAS, V. T.; CERQUEIRA, L. S. Consumidor de baixa renda: uma análise dos fatores que influenciam a aquisição de automóveis em Salvador. In: SIMPÓSIO DE EXCELÊNCIA EM GESTÃO E TECNOLOGIA, 9., 2012, Rezende, RJ. Anais... Rezende, RJ: AEDB, 2012. Não paginado. Disponível em: <http://www.car.aedb.br/seget/artigos12/56416375. pdf>. Acesso em: 5 dez. 2014.

SOLOMON, M. R. Comportamento do consumidor: comprando, possuindo e sendo. 5. ed. Porto Alegre, RS: Bookman, 2002.

SPECTOR, P. Psicologia nas organizações. São Paulo: Saraiva, 2012.

TORRES, C. V.; ALLEN, M. W. Influência da cultura, dos valores humanos e do significado do produto na predição de consumo: síntese de dois estudos multiculturais na Austrália e no Brasil. Revista de Administração do Mackenzie, São Paulo, v. 10, n. 3, p. 127-152, 2009. Disponível em: 
<http://www.scielo.br/pdf/ram/v10n3/a08v10n3.pdf>. Acesso em: 5 dez. 2014.

VASCONCELOS, E. A. O que é trânsito? São Paulo: Brasiliense, 1992. . A cidade, o transporte e o trânsito. São Paulo: Prolivros, 2005. 